\title{
Nomogram for predicting mandatory ICU admission after gastrectomy for gastric cancer
}

\author{
Haoquan Huang, Zhixiao Han, Xia Liang, Yanni Fu, Zhongqi Liu, Minghui Cao \\ Department of Anesthesiology, Sun Yat-sen Memorial Hospital, Sun Yat-sen University, Guangzhou, China \\ Contributions: (I) Conception and design: H Huang, Z Han; (II) Administrative support: M Cao; (III) Provision of study materials or patients: H \\ Huang, X Liang; (IV) Collection and assembly of data: Z Han, X Liang, Y Fu; (V) Data analysis and interpretation: H Huang, Z Han, Z Liu; (VI) \\ Manuscript writing: All authors; (VII) Final approval of manuscript: All authors. \\ Correspondence to: Minghui Cao. NO. 107 Yanjiang West Road, Yuexiu District, Guangzhou, China. Email: caomh@mail.sysu.edu.cn.
}

\begin{abstract}
Background: This study aimed to identify risk factors that were associated with mandatory intensive care unit (ICU) admission after gastrectomy for gastric cancer. We then employed these risk factors to construct and validate a nomogram for predicting mandatory ICU admission after gastrectomy, which may identify those who require ICU indeed and improve ICU utilization.
\end{abstract}

Methods: A number of 999 gastric cancer patients undergoing gastrectomy from January 2010 to June 2019 were included in the retrospective study. Forty-three patients were classified into mandatory ICU admission groups, and the remaining 956 patients were allocated into the no need for ICU admission group. The candidate variables, including patient demographic characteristics, preoperative laboratory tests and surgical variables, were compared between the two groups. We then carried out univariate and multivariate logistic regression analyses to find out risk factors for mandatory ICU admission. In order to develop the predictive model, we used Akaike information criterion (AIC) to select risk factors via a step-down backward process from the multivariate regression model.

Results: A number of risk factors for mandatory ICU admission were identified and subsequently used to build the nomogram: age [odds ratio (OR), 1.03; 95\% CI, 1.00-1.07; P=0.031], ASA status (III-IV vs. III: OR,1.74; 95\% CI, 0.88-3.46; P=0.114), tumor size (OR, 1.28; 95\% CI, 1.08-1.51; $\mathrm{P}=0.004)$, estimated blood loss (OR, 1.001; 95\% CI, 1.000-1.001; P=0.082) as well as intraoperative transfusion (Yes vs. No: OR, $3.82 ; 95 \% \mathrm{CI}, 1.87-7.82 ; \mathrm{P}<0.001)$. C-index of the nomogram was 0.800 , indicating good discrimination. Both Calibration curve and Hosmer-Lemeshow goodness-of-fit tests $(\mathrm{P}=0.128)$ showed that there was a high degree of agreement between the prediction and actual outcome.

Conclusions: A nomogram to predict mandatory ICU admission after gastrectomy for gastric cancer was constructed and validated. Clinicians could apply this predictive model to improve usage of limited ICU resources effectively.

Keywords: Intensive care unit (ICU) admission; gastrectomy; gastric cancer; nomogram

Submitted Dec 30, 2020. Accepted for publication Apr 28, 2021.

doi: $10.21037 / \mathrm{apm}-21-178$

View this article at: http://dx.doi.org/10.21037/apm-21-178

\section{Introduction}

As the fifth most common cancer, gastric cancer is the third leading cause of cancer death around the world (1). Gastrectomy is still the only option for curative treatment for gastric cancer (2). Even though gastrectomy has been performed for several decades $(3,4)$ and surgical and anesthesia techniques have improved, postoperative morbidity and mortality remain high (5-8). Previous researches showed that the morbidity rate after gastrectomy was about $20 \%(6,9)$ and the 30 -day mortality varies from $5.2 \%$ to $12.8 \%(5,6,9)$. Even the serious complications, 
including septic shock and cardiac arrest, were reportedly to occur in $23.6 \%$ following gastrectomy for gastric cancer (5).

Once serious morbidity occurs, a part of these patients will require higher levels of postoperative surveillance and medical management, which may include transferring to intensive care unit (ICU). However, as there is high demand for close monitoring and supportive therapies for high-risk patients, ICU resources are relatively limited $(10,11)$. One possible explanation is that a portion of patients admitted to ICU are only for surveillance purpose, which results in overlooking those who require intensive care in deed. In addition, ICU admission is a main driver of health care costs (12). Thus, in order to improve resource allocation and reduce costs, it is necessary to identify patients who may require mandatory ICU admission after gastrectomy for gastric cancer.

Previous studies have developed surgical Apgar score to predict postoperative ICU admission after general surgery $(13,14)$. However, both of the previous studies have not distinguished mandatory ICU admission from unnecessary ICU admission. Mandatory ICU admission was defined as meeting at least one of the following criteria: acute respiratory failure, hemodynamic instability, using a variety of vasoactive drugs, maintenance of mechanical ventilation and reintubation. Unnecessary ICU admission was defined as immediately transferring to ICU after operation only for the purpose of surveillance and subsequently transferred to the general ward the day after operation. A previous study has found that age, American Society of Anesthesiologists (ASA) status, and duration of procedure were associated with unplanned ICU admission after surgery (12), which is classified as mandatory ICU admission. However, there is no study focusing on risk factors of mandatory ICU admission after gastrectomy. With regard to the scare ICU resources and the high risk of gastrectomy, there is a need to study the risk factors and develop a predictive model for mandatory ICU admission after gastrectomy for gastric cancer.

Nomogram is a practical tool for clinicians to predict each patient's outcome $(15,16)$. This study aimed to identify risk factors for mandatory ICU admission and use them to develop a nomogram for predicting mandatory ICU admission after gastrectomy for gastric cancer.

We present the following article in accordance with the STROBE reporting checklist (available at http://dx.doi. org/10.21037/apm-21-178).

\section{Methods}

\section{Patients}

The study was conducted in accordance with the Declaration of Helsinki (as revised in 2013). The study was approved by Institutional Ethics Committee of Sun Yat-sen Memorial Hospital (NO. SYSEC-KY-KS-2020-185) and individual consent for this retrospective analysis was waived. All consecutive patients who underwent gastrectomy for pathological diagnosed gastric adenocarcinoma from January 2010 to June 2019 in Sun Yat-sen Memorial Hospital were extracted from the electronic database. Patients were excluded if they had one of the following features: under the age of 18 , underwent gastrectomy previously, admitted to ICU preoperatively, had blood transfusion preoperatively, had neoadjuvant chemotherapy preoperatively, emergency surgery, palliative gastrectomy, had other synchronous cancers and missing data. Emergency surgery was an emergency operation carried out within $12 \mathrm{~h}$ after admitting to hospital or after the onset of associated symptoms. After selection, a total of 999 patients were eligible for analysis.

\section{Data collection}

Patient demographic characteristics including age, sex, weight, ASA status, Charlson comorbidity index (CCI) score as well as comorbidities were extracted. Preoperative laboratory examinations such as hemoglobin, platelet and albumin were also extracted. In addition, tumor size, location and stage were also included in this study. Surgeryrelated variables, such as type of gastrectomy, approach method, extragastric organ resection, estimated blood loss and operation time, were obtained from the database. Postoperative variables included intensive care unit (ICU) admission, postoperative length of stay, complications, Clavien-Dindo severity classification of complications and in-hospital mortality. The detailed definitions of variables are presented in Table S1.

\section{Primary outcome}

The primary outcome was mandatory ICU admission. Since there are no existing criteria for mandatory ICU admission after gastrectomy, we defined the mandatory ICU admission criteria in this study referring to the definition 
in other surgical fields $(12,17)$, as well as the practice in our hospital. It was defined as meeting at least one of the following criteria: acute respiratory failure, hemodynamic instability, using a variety of vasoactive drugs, maintenance of mechanical ventilation and reintubation. These features highlighted the specific needs that can be only addressed in the ICU environment, which is consistent with the ICU admission guideline (18). Patients who were admitted to ICU postoperatively were classified into three subgroups: (I) unnecessary ICU admission group: patients immediately transferred to ICU only for the purpose of surveillance and subsequently transferred to the general ward the day after operation; (II) necessary ICU admission group: those admitted to ICU immediately postoperatively and met the requirement of mandatory ICU admission; (III) unplanned ICU admission group: those who admitted to general ward immediately postoperatively and transferred to ICU following the presence of emergent situations, such as sepsis shock and cardiac arrest, requiring intensive care. The mandatory ICU admission group included (II) necessary ICU admission group and (III) unplanned ICU admission group.

\section{Statistical analysis}

Univariate and multivariate logistic regression analyses were carried out to find out risk factors for mandatory ICU admission after gastrectomy. Only variables with $\mathrm{P}<0.02$ were selected into the multivariate logistic regression analyses. Variance inflation factor (VIF) was employed to detect whether there was multicollinearity in multivariate logistic regression analysis. If VIF was above 10 , the variable was considered to have multicollinearity.

The Akaike information criterion (AIC) was used to choose risk factors from the full multivariate regression model. Specifically, AIC is a selection criterion that creates the best-fit model which explains the greatest amount of variation using the fewest possible independent variables. Subsequently, we incorporated the selected variables into the nomogram to predict mandatory ICU admission after gastrectomy.

The concordance index (C-index) was employed to evaluate the discrimination of nomogram. And then a calibration curve was used to estimate the calibration through utilizing 1,000 bootstrap resamples.

The $t$-test or the Mann-Whitney U-tests was employed to assess the continuous variables according to the normality of variables. The chi-square test or the Fisher exact test was used to assess the categorical variables according to the frequencies of variables. All statistical analyses were performed through $\mathrm{R}$ software version 3.4.2 (Institute for Statistics and Mathematics, Vienna, Austria; https:// www.r-project.org/), and a two-tailed $\mathrm{P}$ value $<0.05$ was considered to be statistically significant.

\section{Results}

\section{Patients' baseline characteristics}

A total of 999 gastric cancer patients with gastrectomy were eligible for the analysis. Among the 999 patients, 956 (95.7\%) patients were in the no need for ICU admission group and 43 (4.3\%) patients were in the mandatory ICU admission group (Figure 1). Specifically, the patients in the unplanned ICU admission within 3 days after operation group were transferred to ICU on postoperative day 3.0 (2.0-10.0). The reason, the postoperative day of transferring to ICU and the length of ICU stay in unplanned ICU admission group were listed in Table 1. Among the 25 patients, eight of them admitted to ICU after reoperation for intraabdominal bleeding [length of ICU stay: 3.5 (3.0-4.75) days], seven of them were admitted due to the pulmonary infection [3.0 (3.0-4.5) days], four of them were transferred to ICU due to sepsis [9.0 (8.0-10.75) days].

Table 2 displayed all variables stratified by the ICU status. Patients in the mandatory ICU admission group were prone to be older [median age in patients with transfusion 69.0 (61.5-74.0) vs. 59.0 (51.0-66.0) years in those without; $\mathrm{P}<0.001$ ], to have higher ASA status (ASA III-IV: $65.1 \%$ vs. $35.5 \% ; \mathrm{P}<0.001)$ and higher CCI scores (CCI $\geq 4: 81.4 \%$ vs. $50.6 \% ; \mathrm{P}<0.001)$. The size of tumor in the mandatory ICU group were significantly greater than the one in the no need for ICU admission group [5.86 (4.31-7.11) vs. $4.62(2.98-6.38) \mathrm{cm} ; \mathrm{P}=0.005]$. Moreover, patients in the mandatory ICU admission group were more likely to have extragastric organ resection $(30.2 \%$ vs. $13.2 \% ; \mathrm{P}=0.003)$. Regarding preoperative laboratory tests, patients in the mandatory ICU group had lower hemoglobin level $\{110$ [88-139] vs. $124[102-139] \mathrm{g} / \mathrm{L} ; \mathrm{P}<0.001\}$. With regard to surgical and postoperative variables, patients in the mandatory ICU group had more estimated blood loss $\{200[100-400]$ vs. $100[100-200] \mathrm{mL} ; \mathrm{P}<0.001\}$ and were more likely to have intraoperative transfusion $(53.5 \%$ vs. 26.6\%; $\mathrm{P}=0.003)$. Compared to those in the no ICU admission group, the amount of total fluid was similar $\{2,250$ $[2,000-2,750]$ vs. $2,000[1,750-2,500] \mathrm{mL} ; \mathrm{P}=0.135\}$ and 


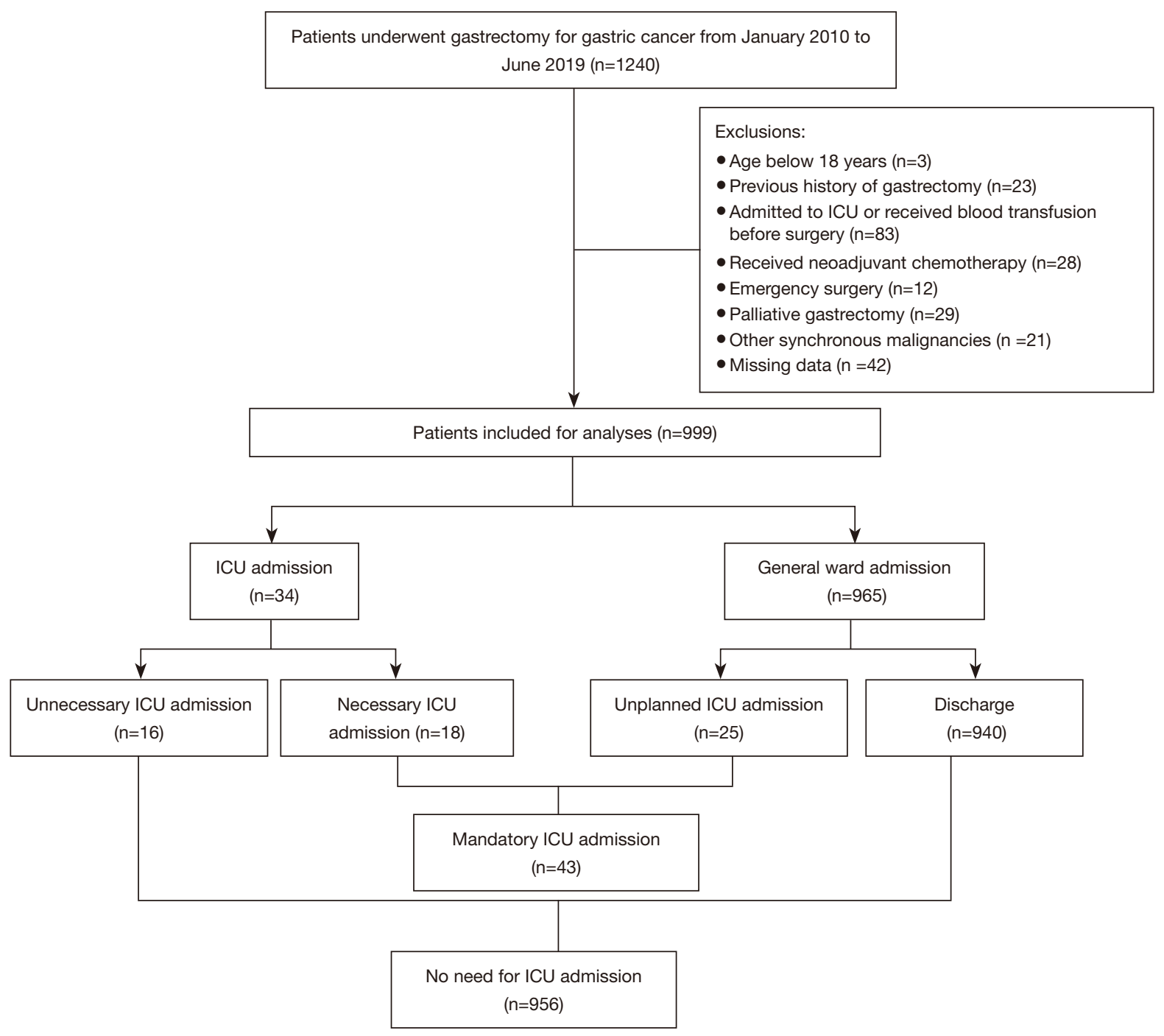

Figure 1 Flowchart of patient selection.

the intraoperative infusion rate was faster $[10.1(8.06-12.5)$ vs. $9.22(6.87-11.8) \mathrm{mL} / \mathrm{kg} / \mathrm{h} ; \mathrm{P}=0.068]$ in patients with mandatory ICU admission. In addition, patients in the mandatory ICU group had longer postoperative length of stay [17.0 (11.5-27.0) vs. $12.0(9.0-15.0)$ days; $\mathrm{P}<0.001]$, more complications $(30.2 \%$ vs. $11.1 \% ; \mathrm{P}<0.001)$ and higher mortality rate $(16.3 \%$ vs. $0.3 \% ; \mathrm{P}<0.001)$. When it comes to the severity classification of complications, patients with mandatory ICU admission were more likely to have severer complications (grade III or greater: $23.2 \%$ vs. $4.4 \%$, $\mathrm{P}<0.001)$.

Incidences of abscess, ileus, anastomotic leakage, intestinal obstruction, intraabdominal bleeding, pulmonary infection, pleural effusion, pulmonary failure and cardiac failure were significantly higher in the mandatory ICU admission group, compared to the no need for ICU admission group (Table 3).

\section{Univariate and multivariate analysis}

Table 4 displayed the univariate and multivariate analyses. In univariate analyses, age, ASA status, CCI score, tumor size, extragastric organ resection, preoperative hemoglobin, preoperative albumin level, estimated blood loss and intraoperative transfusion were significantly associated with mandatory ICU admission in gastric patients undergoing gastrectomy. In AIC-based multivariate analysis, age, ASA status, tumor size, estimated blood loss and intraoperative 
Table 1 Reason, the postoperative day of transferring to ICU and the length of ICU stay in unplanned ICU admission group

\begin{tabular}{|c|c|c|c|}
\hline ICU type & Reason & $\begin{array}{l}\text { The postoperative day of transferring } \\
\text { to ICU }\end{array}$ & $\begin{array}{l}\text { Length of ICU stay (days), } \\
\text { median [Q1, Q3] }\end{array}$ \\
\hline \multirow[t]{6}{*}{ Unplanned ICU admission $(n=25)$} & & $3.0[2.0,10.0]$ & $4.0[3.0,8.0]$ \\
\hline & Pulmonary infection $(n=7)$ & $5.0[2.5,8.5]$ & $3.0[3.0,4.5]$ \\
\hline & Pneumothorax $(n=1)$ & $2.0^{*}$ & $9.0^{*}$ \\
\hline & Renal failure $(n=1)$ & $2.0^{\star}$ & $9.0^{*}$ \\
\hline & Cardiac failure $(n=2)$ & $1.0^{*}$ & $8.0^{\star}$ \\
\hline & Sepsis $(n=4)$ & $9.5[4.25,13.25]$ & $9.0[8.0,10.75]$ \\
\hline
\end{tabular}

*, shown as median without [Q1, Q3] due to the limited sample size.

transfusion were found out to be independent risk factors for mandatory ICU admission in gastric patients undergoing gastrectomy.

\section{Construction and validation of nomogram}

The identified risk factors in AIC-based multivariate analysis were employed to construct the nomogram to predict mandatory ICU admission for gastric cancer surgery (Figure 2).

The C-index of the nomogram was 0.800 , indicating high accuracy in predicting the risk of mandatory ICU admission. The C-indexes for each risk factor employed in the nomogram were shown in Table 5. While age had the strongest prediction ability with C-index 0.728 , tumor size had the lowest C-index 0.626. Calibration curve was employed to assess the calibration (Figure 3). What's more, $\mathrm{P}$ values for the Hosmer-Lemeshow goodness-of-fit test was 0.128 . Both the calibration curve and the HosmerLemeshow goodness-of-fit test showed that there was a high degree of agreement between the prediction and actual outcome.

\section{Discussion}

Gastrectomy is the only option for curative treatment for gastric cancer. Due to its significant morbidity, ICU admission is needed in a part of cancer patients with gastrectomy. In this study, $4.3 \%$ of total patients were in the mandatory ICU admission group. This study demonstrated that age, ASA status, tumor size, estimated blood loss and intraoperative transfusion were independent risk factors for predicting mandatory ICU admission after gastric cancer surgery. Communication between surgeons, anesthesiologists and intensivists is essential to improve utilization of ICU resources. The nomogram developed in this study could be served as an easy-to-use tool to screen those who may require mandatory ICU admission after gastric cancer surgery.

There are several differences between our study and previous studies about predicting ICU admission after surgery $(15,18)$. Firstly, a study by Sobol et al. merely focused on immediate ICU admission after high-risk intraabdominal surgery (13). In this study, while $41.9 \%$ of patients with mandatory ICU admission admitted immediately after surgery, $58.1 \%$ transferred to ICU from general ward (Figure 1). This result suggested that unplanned ICU admission after gastrectomy accounted for a large part of ICU admission. Thus, unplanned ICU admission should be taken into account when developing a predictive tool for ICU admission postoperatively. Secondly, a study by Glass et al. included both immediate ICU admission patients and unplanned ICU admission patients (14). However, among patients with immediate ICU admission, this previous study has not distinguished between necessary and unnecessary ICU admission. In contrast, unnecessary ICU admission was defined as no need for ICU admission in this study, since it was only for surveillance purpose and subsequently resulted in overlooking those who require intensive care in deed. Thirdly, both of the previous studies 
Table 2 Patient characteristics

\begin{tabular}{|c|c|c|c|}
\hline Characteristics & No ICU admission ( $n=956)$ & Mandatory ICU admission $(n=43)$ & $P$ \\
\hline Median [Q1, Q3] & $59.0[51.0,66.0]$ & $69.0[61.5,74.0]$ & $<0.001^{\dagger}$ \\
\hline \multicolumn{4}{|l|}{ Sex } \\
\hline Female & 324 (33.9\%) & $13(30.2 \%)$ & $0.740^{\star}$ \\
\hline \multicolumn{4}{|l|}{ Weight (kg) } \\
\hline Median [Q1, Q3] & $58.0[51.0,65.0]$ & $56.0[50.0,60.0]$ & $0.306^{\dagger}$ \\
\hline \multicolumn{4}{|l|}{ ASA status } \\
\hline I-II & $617(64.5 \%)$ & $15(34.9 \%)$ & $<0.001^{\star}$ \\
\hline III-IV & $339(35.5 \%)$ & $28(65.1 \%)$ & \\
\hline$\geq 4$ & $484(50.6 \%)$ & $35(81.4 \%)$ & \\
\hline \multicolumn{4}{|l|}{ Comorbidities } \\
\hline No & $772(80.8 \%)$ & $30(69.8 \%)$ & $0.115^{\star}$ \\
\hline Yes & $184(19.2 \%)$ & $13(30.2 \%)$ & \\
\hline \multicolumn{4}{|l|}{ Tumor size (cm) } \\
\hline Median [Q1, Q3] & $4.62[2.98,6.38]$ & $5.86[4.31,7.11]$ & $0.005^{\dagger}$ \\
\hline \multicolumn{4}{|l|}{ Tumor location } \\
\hline Upper & $115(12.0 \%)$ & $5(11.6 \%)$ & $0.900^{*}$ \\
\hline III & $534(55.9 \%)$ & $25(58.1 \%)$ & \\
\hline \multicolumn{4}{|l|}{ LN dissection } \\
\hline D1/D1+ & $154(16.1 \%)$ & $7(16.3 \%)$ & $1.000^{*}$ \\
\hline D2/D2+ & $802(83.9 \%)$ & $36(83.7 \%)$ & \\
\hline \multicolumn{4}{|l|}{ Type of gastrectomy } \\
\hline Total & $258(27.0 \%)$ & $14(32.6 \%)$ & $0.530^{*}$ \\
\hline Subtotal & $698(73.0 \%)$ & $29(67.4 \%)$ & \\
\hline \multicolumn{4}{|l|}{ Approach method } \\
\hline Laparoscopy & 357 (37.3\%) & $12(27.9 \%)$ & $0.275^{\star}$ \\
\hline Open & $599(62.7 \%)$ & $31(72.1 \%)$ & \\
\hline \multicolumn{4}{|c|}{ Extragastric organ resection } \\
\hline No & $830(86.8 \%)$ & $30(69.8 \%)$ & $0.003^{*}$ \\
\hline Yes & $126(13.2 \%)$ & $13(30.2 \%)$ & \\
\hline
\end{tabular}

Table 2 (continued) 
Table 2 (continued)

\begin{tabular}{|c|c|c|c|}
\hline Characteristics & No ICU admission ( $n=956)$ & Mandatory ICU admission $(n=43)$ & $\mathrm{P}$ \\
\hline \multicolumn{4}{|c|}{ Preoperative hemoglobin (g/L) } \\
\hline Median [Q1, Q3] & $124[102,139]$ & $110[88,139]$ & $<0.001^{\dagger}$ \\
\hline \multicolumn{4}{|l|}{ Preoperative INR } \\
\hline Median [Q1, Q3] & $1.01[0.960,1.06]$ & $1.02[0.970,1.08]$ & $0.414^{\dagger}$ \\
\hline \multicolumn{4}{|c|}{ Preoperative platelet $\left(\times 10^{9} / L\right)$} \\
\hline \multicolumn{4}{|c|}{ Preoperative albumin (g/L) } \\
\hline Median [Q1, Q3] & $39.6[36.2,42.7]$ & $39.3[32.7,42.6]$ & $0.145^{\dagger}$ \\
\hline \multicolumn{4}{|c|}{ Estimated blood loss (mL) } \\
\hline Median [Q1, Q3] & $100[100,200]$ & $200[100,400]$ & $<0.001$ \\
\hline Yes & $254(26.6 \%)$ & $23(53.5 \%)$ & \\
\hline \multicolumn{4}{|l|}{ Total fluid (mL) } \\
\hline Median [Q1, Q3] & $2,000[1,750,2,500]$ & $2,250[2,000,2,750]$ & $0.135^{\dagger}$ \\
\hline \multicolumn{4}{|l|}{ Total crystalloid (mL) } \\
\hline Median [Q1, Q3] & $1,250[1,000,1,500]$ & $1,000[1,000,1,500]$ & $0.058^{\dagger}$ \\
\hline \multicolumn{4}{|l|}{ Total colloid (mL) } \\
\hline Median [Q1, Q3] & $1,000[500,1,030]$ & $1,000[1,000,1,500]$ & $<0.001^{\dagger}$ \\
\hline \multicolumn{4}{|c|}{ Intraoperative infusion rate $(\mathrm{mL} / \mathrm{kg} / \mathrm{h})$} \\
\hline Median [Q1, Q3] & $9.22[6.87,11.8]$ & $10.1[8.06,12.5]$ & $0.068^{\dagger}$ \\
\hline \multicolumn{4}{|l|}{ Operation time (min) } \\
\hline No & $850(88.9 \%)$ & $30(69.8 \%)$ & $<0.001^{*}$ \\
\hline Yes & $106(11.1 \%)$ & $13(30.2 \%)$ & \\
\hline \multicolumn{4}{|c|}{ Clavien-Dindo severity classification of complications } \\
\hline None & $850(88.9 \%)$ & $30(69.8 \%)$ & $<0.001^{*}$ \\
\hline Grade II & $64(6.7 \%)$ & $3(7.0 \%)$ & \\
\hline Grade III or greater & $42(4.4 \%)$ & $10(23.2 \%)$ & \\
\hline \multicolumn{4}{|l|}{ In hospital mortality } \\
\hline No & $953(99.7 \%)$ & $36(83.7 \%)$ & $<0.001^{*}$ \\
\hline Yes & $3(0.3 \%)$ & $7(16.3 \%)$ & \\
\hline
\end{tabular}

*, chi-squared test or Fisher exact test; ${ }^{\dagger}$, Mann-Whitney $U$ test. ASA status, the American Society of Anesthesiologists physical status; $\mathrm{CCI}$, Charlson comorbidity index; cTNM stage, Clinical Tumor-Lymph Node-Metastasis; LN dissection, lymph node dissection; INR, international normalized ratio; ICU, intensive care unit. 
Table 3 Comparison of complications between no need for ICU admission group and mandatory ICU admission group

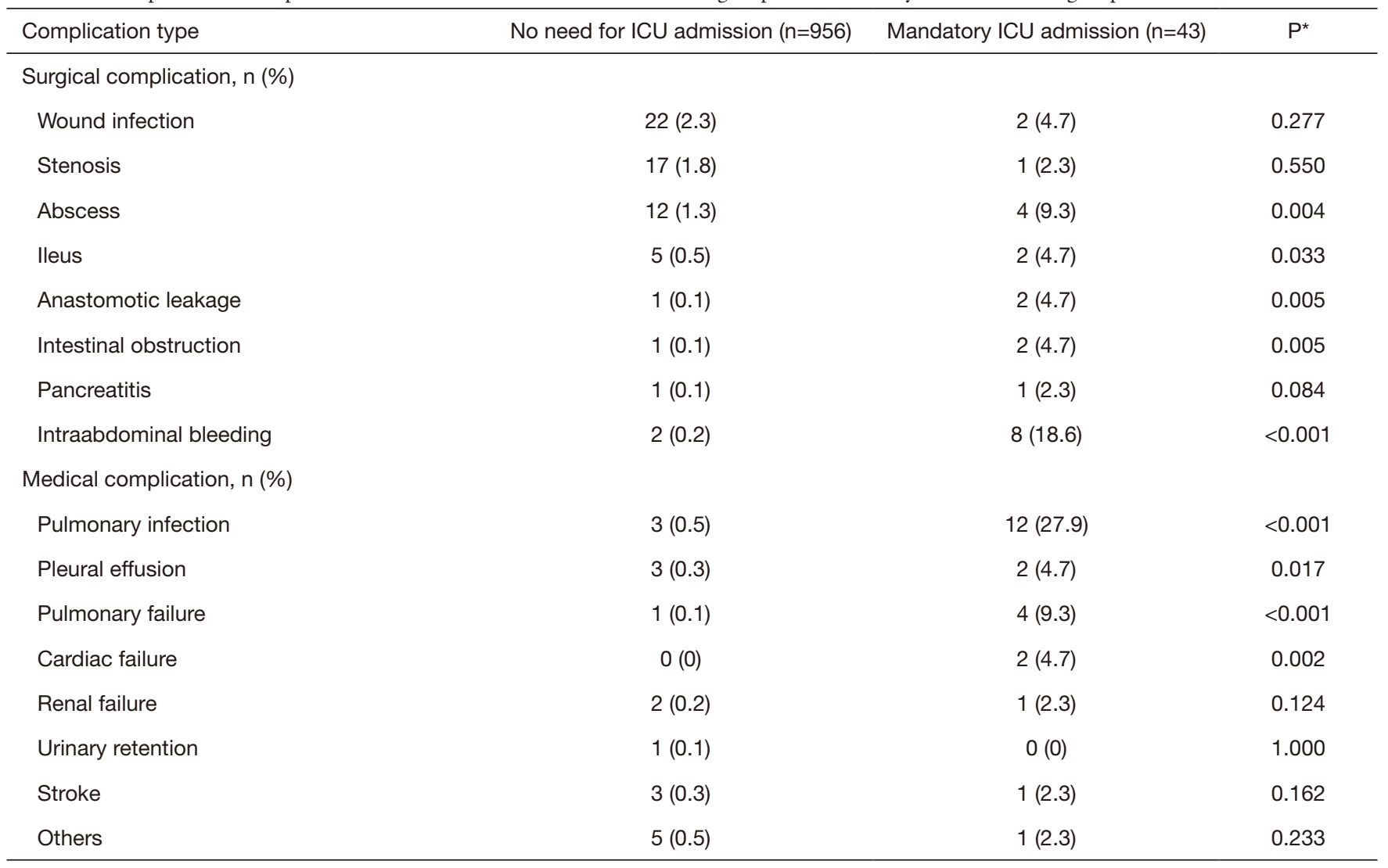

*, calculated by Fisher exact test.

merely included intraoperative factors such as heart rate, mean arterial blood pressure and estimated blood loss as predictive variables for ICU admission. On the contrary, preoperative and intraoperative factors were employed to identified risk factors for mandatory ICU admission in this study. The C-indexes for preoperative factors such as age and ASA status were even greater than the intraoperative transfusion. This result indicated that preoperative factors were as important as intraoperative factors for predicting mandatory ICU admission after gastrectomy for gastric cancer.

Previous studies have shown that advanced age and ASA classification were independent risk factors for mortality and morbidity after gastrectomy $(6,19,20)$. In this study, age and ASA status were significantly associated with increased risk of mandatory ICU admission. In addition, age had the highest $\mathrm{C}$-index compared to other variables in this study, indicating that age played a major role in predicting mandatory ICU admission after gastrectomy.
In our study, patients with mandatory admission were associated with more complications, which is consistent with previous findings (21-23). Pulmonary complications were the main reason for unplanned ICU admission. Additionally, pulmonary complications were one of the most common complications following gastrectomy $(6,24)$. Thus, early identification and prevention of pulmonary complications is needed in terms of improving postoperative outcomes and reducing risk of unplanned ICU admission after gastrectomy.

There are several limitations in this study. Firstly, the nomogram has inherent limitations because it was based on a retrospective study using database from a single hospital. In view of this point, it is necessary to carry out a multicenter prospective cohort study to verify the results in this study. Secondly, this study merely focused on patients with malignancy. To develop a generalized predictive model, patients requiring gastrectomy for benign diseases will be included in our future study. 
Table 4 Univariable and multivariable logistic regression analysis of factors associated with mandatory ICU admission

\begin{tabular}{|c|c|c|c|c|c|c|}
\hline \multirow{2}{*}{ Characteristics } & \multicolumn{2}{|c|}{ Univariable logistic regression* } & \multicolumn{2}{|c|}{ Multivariable logistic regression } & \multicolumn{2}{|c|}{$\begin{array}{c}\text { AIC-based multivariable logistic } \\
\text { regression }\end{array}$} \\
\hline & OR $(95 \% \mathrm{Cl})$ & $\mathrm{P}$ & OR $(95 \% \mathrm{Cl})$ & $\mathrm{P}$ & OR $(95 \% \mathrm{Cl})$ & $\mathrm{P}$ \\
\hline Age (years) & $1.08(1.05-1.11)$ & $<0.001$ & $1.04(0.99-1.08)$ & 0.096 & $1.03(1.00-1.07)$ & 0.031 \\
\hline \multicolumn{7}{|l|}{ Sex } \\
\hline Male & $1.18(0.62-2.38)$ & 0.620 & - & - & - & - \\
\hline Weight (kg) & $0.99(0.96-1.02)$ & 0.436 & - & - & - & - \\
\hline \multicolumn{7}{|l|}{ ASA status } \\
\hline$I-I I$ & Reference & & Reference & & Reference & \\
\hline$\geq 4$ & $4.27(2.06-9.98)$ & $<0.001$ & $0.91(0.31-2.60)$ & 0.853 & - & - \\
\hline \multicolumn{7}{|l|}{ Comorbidities } \\
\hline No & Reference & & - & & - & \\
\hline Yes & $1.82(0.90-3.48)$ & 0.081 & - & - & - & - \\
\hline Tumor size $(\mathrm{cm})$ & $1.26(1.08-1.49)$ & 0.005 & $1.28(1.08-1.51)$ & 0.004 & $1.28(1.08-1.51)$ & 0.004 \\
\hline \multicolumn{7}{|l|}{ Tumor location } \\
\hline Upper & Reference & & - & & - & - \\
\hline II & $1.26(0.49-3.36)$ & 0.631 & - & - & - & \\
\hline III & $1.32(0.61-3.16)$ & 0.507 & - & - & - & \\
\hline \multicolumn{7}{|l|}{ LN dissection } \\
\hline D1/D1+ & Reference & & - & & - & \\
\hline D2/D2+ & $0.99(0.46-2.46)$ & 0.976 & - & - & - & - \\
\hline \multicolumn{7}{|c|}{ Type of gastrectomy } \\
\hline Total & Reference & & - & & - & \\
\hline Subtotal & $0.77(0.41-1.51)$ & 0.423 & - & - & - & - \\
\hline \multicolumn{7}{|c|}{ Approach method } \\
\hline Laparoscopy & Reference & & - & & - & \\
\hline Open & $1.54(0.80-3.15)$ & 0.213 & - & - & - & - \\
\hline
\end{tabular}

Table 4 (continued) 
Table 4 (continued)

\begin{tabular}{|c|c|c|c|c|c|c|}
\hline \multirow{2}{*}{ Characteristics } & \multicolumn{2}{|c|}{ Univariable logistic regression* } & \multicolumn{2}{|c|}{ Multivariable logistic regression } & \multicolumn{2}{|c|}{$\begin{array}{l}\text { AIC-based multivariable logistic } \\
\text { regression }\end{array}$} \\
\hline & OR $(95 \% \mathrm{Cl})$ & $\mathrm{P}$ & OR $(95 \% \mathrm{Cl})$ & $\mathrm{P}$ & OR $(95 \% \mathrm{Cl})$ & $\mathrm{P}$ \\
\hline No & Reference & & Reference & & - & \\
\hline Preoperative INR & $7.87(0.37-96.5)$ & 0.139 & - & - & - & - \\
\hline Preoperative platelet $\left(\times 10^{9} / L\right)$ & $1.002(0.999-1.004)$ & 0.255 & - & - & - & - \\
\hline Preoperative albumin (g/L) & $0.93(0.88-0.98)$ & 0.011 & $1.01(0.95-1.07)$ & 0.870 & - & - \\
\hline Yes & $3.12(1.72-5.93)$ & $<0.001$ & $3.83(1.84-7.98)$ & $<0.001$ & $3.82(1.87-7.82)$ & $<0.001$ \\
\hline $\begin{array}{l}\text { Intraoperative infusion rate } \\
(\mathrm{mL} / \mathrm{kg} / \mathrm{h})\end{array}$ & $1.06(0.98-1.13)$ & 0.115 & - & - & - & - \\
\hline Operation time (mins) & $1.001(0.997-1.005)$ & 0.481 & - & - & - & - \\
\hline
\end{tabular}

*, performed with each single variable with different classifications. ASA status, the American Society of Anesthesiologists physical status; CCI, Charlson comorbidity index; cTNM stage, Clinical Tumor-Lymph Node-Metastasis; LN dissection, lymph node dissection; INR, international normalized ratio; ICU, intensive care unit.

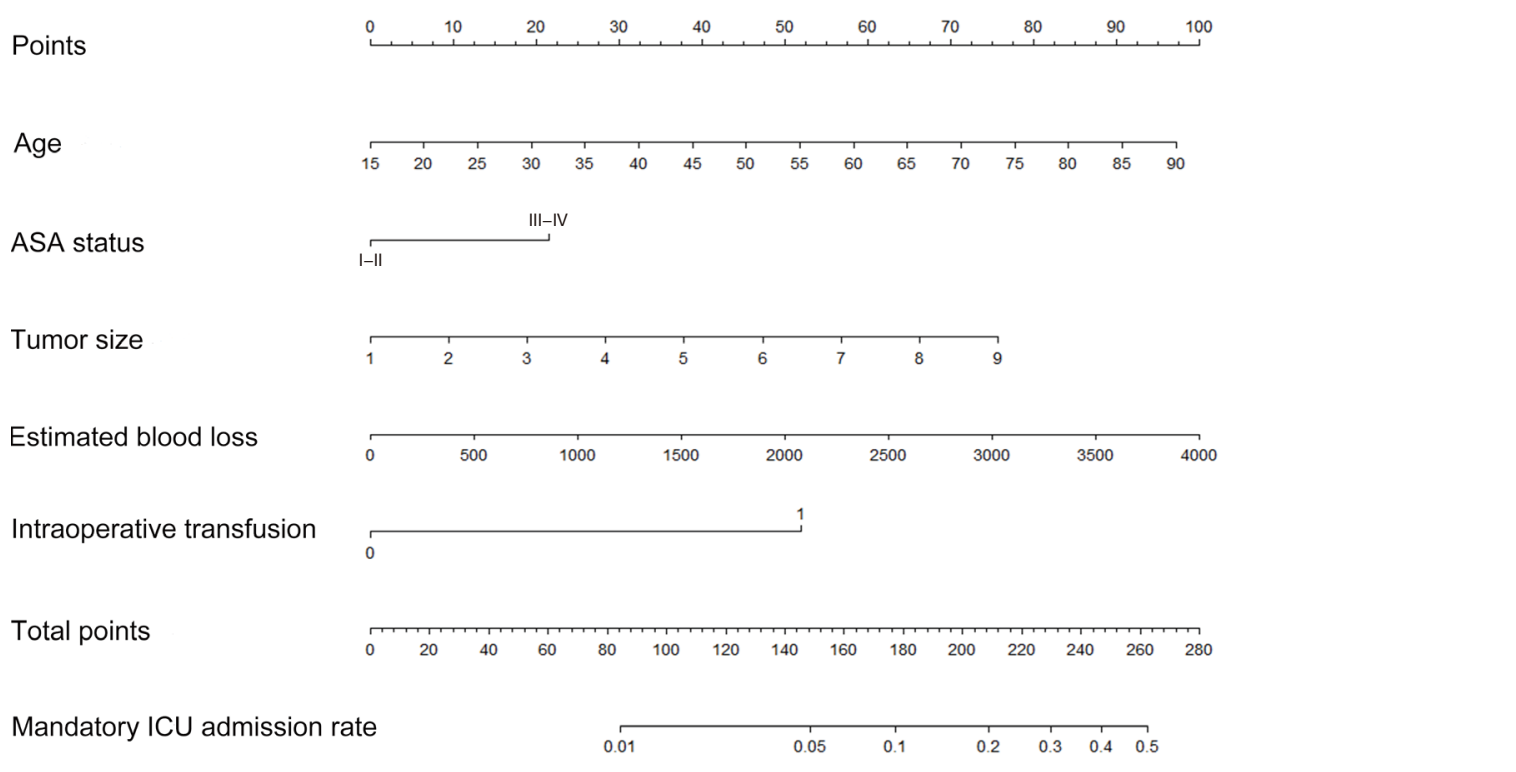

Figure 2 Nomogram predicting the probability of mandatory ICU admission after gastrectomy for gastric cancer. ASA status, the American Society of Anesthesiologists physical status. 
Table 5 C-index for nomogram and each predictor of the nomogram

\begin{tabular}{lc}
\hline Predictor & C-index \\
\hline Nomogram & 0.800 \\
Age & 0.728 \\
Estimated blood loss & 0.681 \\
ASA status & 0.648 \\
Intraoperative transfusion & 0.635 \\
Tumor size & 0.626 \\
\hline
\end{tabular}

ASA, American Society of Anesthesiologists.

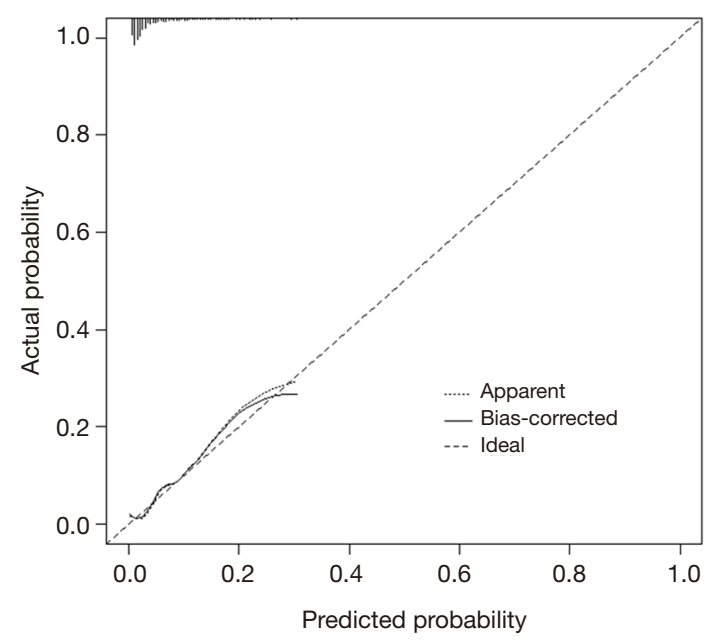

Figure 3 Calibration curve of the nomogram.

\section{Conclusions}

In this study, a nomogram was developed and validated to predict the probability of mandatory ICU admission after gastric cancer surgery. Appropriate use of the nomogram in this study may identify those who require ICU indeed, improving patient safety and ICU utilization.

\section{Acknowledgments}

The authors acknowledge the support of Dr. Zhu Liang from The Third Affiliated Hospital of Guangzhou Medical University for assistance in the editing of this manuscript. Funding: This work was supported by the Guangzhou Science and Technology Project (No. 202002020002).

\section{Footnote}

Reporting Checklist: The authors have completed the STROBE reporting checklist. Available at http://dx.doi. org/10.21037/apm-21-178

Data Sharing Statement: Available at http://dx.doi. org/10.21037/apm-21-178.

Conflicts of Interest: All authors have completed the ICMJE uniform disclosure form (available at http://dx.doi. org/10.21037/apm-21-178). The authors have no conflicts of interest to declare.

Etbical Statement: The authors are accountable for all aspects of the work in ensuring that questions related to the accuracy or integrity of any part of the work are appropriately investigated and resolved. The study was conducted in accordance with the Declaration of Helsinki (as revised in 2013). The study was approved by Institutional Ethics Committee of Sun Yat-sen Memorial Hospital (NO. SYSEC-KY-KS-2020-185) and individual consent for this retrospective analysis was waived.

Open Access Statement: This is an Open Access article distributed in accordance with the Creative Commons Attribution-NonCommercial-NoDerivs 4.0 International License (CC BY-NC-ND 4.0), which permits the noncommercial replication and distribution of the article with the strict proviso that no changes or edits are made and the original work is properly cited (including links to both the formal publication through the relevant DOI and the license). See: https://creativecommons.org/licenses/by-nc-nd/4.0/.

\section{References}

1. Bray F, Ferlay J, Soerjomataram I, et al. Global cancer statistics 2018: GLOBOCAN estimates of incidence and mortality worldwide for 36 cancers in 185 countries. CA Cancer J Clin 2018; 68:394-424.

2. Van Cutsem E, Sagaert X, Topal B, et al. Gastric cancer. Lancet 2016; 388:2654-64.

3. McNeer G, Bowden L, Booner RJ, et al. Elective total gastrectomy for cancer of the stomach: end results. Ann Surg 1974;180:252-6.

4. Kitano S, Iso Y, Moriyama M, et al. Laparoscopy-assisted 
Billroth I gastrectomy. Surg Laparosc Endosc 1994;4:146.

5. Papenfuss WA, Kukar M, Oxenberg J, et al. Morbidity and mortality associated with gastrectomy for gastric cancer. Ann Surg Oncol 2014;21:3008-14.

6. Nelen SD, Bosscha K, Lemmens VEPP, et al. Morbidity and mortality according to age following gastrectomy for gastric cancer. Br J Surg 2018;105:1163-70.

7. Park JH, Lee HJ, Oh SY, et al. Prediction of postoperative mortality in patients with organ failure after gastric cancer surgery. World J Surg 2020;44:1569-77.

8. Hsueh SW, Liu KH, Hung CY, et al. Significance of the glasgow prognostic score in predicting the postoperative outcome of patients with stage III gastric cancer. J Clin Med 2019;8:1448.

9. Martin AN, Das D, Turrentine FE, et al. Morbidity and mortality after gastrectomy: Identification of modifiable risk factors. J Gastrointest Surg 2016;20:1554-64.

10. Wong DJN, Popham S, Wilson AM, et al. Postoperative critical care and high-acuity care provision in the United Kingdom, Australia, and New Zealand. Br J Anaesth 2019;122:460.

11. Adhikari NK, Fowler RA, Bhagwanjee S, et al. Critical care and the global burden of critical illness in adults. Lancet 2010;376:1339-46.

12. Quinn TD, Gabriel RA, Dutton RP, et al. Analysis of unplanned postoperative admissions to the intensive care unit. J Intensive Care Med 2017;32:436-43.

13. Sobol JB, Gershengorn HB, Wunsch H, et al. The surgical apgar score is strongly associated with intensive care unit admission after High-Risk intraabdominal surgery. Anesth Analg 2013;117:438-46.

14. Glass NE, Pinna A, Masi A, et al. The surgical apgar score predicts postoperative ICU admission. J Gastrointest Surg 2015;19:445-50.

15. Huang H, Wang C, Ji F, et al. Nomogram based on albumin and neutrophil-to-lymphocyte ratio for predicting postoperative complications after

Cite this article as: Huang $\mathrm{H}, \mathrm{Han} \mathrm{Z}$, Liang $\mathrm{X}, \mathrm{Fu} \mathrm{Y}$, Liu Z, Cao M. Nomogram for predicting mandatory ICU admission after gastrectomy for gastric cancer. Ann Palliat Med 2021;10(6):6208-6219. doi: 10.21037/apm-21-178 pancreaticoduodenectomy. Gland Surg 2021;10:877-91.

16. Liu Z, Wu H, Liufu N, et al. Development and validation of a nomogram incorporating selected systemic inflammation-based prognostic marker for complication prediction after vascularized fibula flap reconstruction. Oral Oncol 2019; 99:104467.

17. Kim SH, Na S, Park SY, et al. Perioperative Factors for Predicting the Need for Postoperative Intensive Care after Major Lung Resection. J Clin Med 2019;8:744.

18. Nates JL, Nunnally M, Kleinpell R, et al. ICU Admission, Discharge, and Triage Guidelines: A Framework to Enhance Clinical Operations, Development of Institutional Policies, and Further Research. Crit Care Med 2016;44:1553-602.

19. Selby LV, Vertosick EA, Sjoberg DD, et al. Morbidity after Total Gastrectomy: Analysis of 238 Patients. J Am Coll Surg 2015;220:863-71.e2.

20. Turrentine FE, Denlinger CE, Simpson VB, et al. Morbidity, mortality, cost, and survival estimates of gastrointestinal anastomotic leaks. J Am Coll Surg 2015;220:195-206.

21. International Surgical Outcomes Study group: Global patient outcomes after elective surgery: Prospective cohort study in 27 low-, middle- and high-income countries. Br J Anaesth 2017;119:553.

22. Kahan BC, Koulenti D, Arvaniti K, et al. Critical care admission following elective surgery was not associated with survival benefit: Prospective analysis of data from 27 countries. Intensive Care Med 2017;43:971-9.

23. Hamakawa T, Kurokawa Y, Mikami J, et al. Risk factors for postoperative complications after gastrectomy in gastric cancer patients with comorbidities. Surg Today 2016;46:224-8.

24. Kim SM, Youn HG, An JY, et al. Comparison of open and laparoscopic gastrectomy in elderly patients. J Gastrointest Surg 2018; 22:785-91. 
Table S1 Definitions of variables

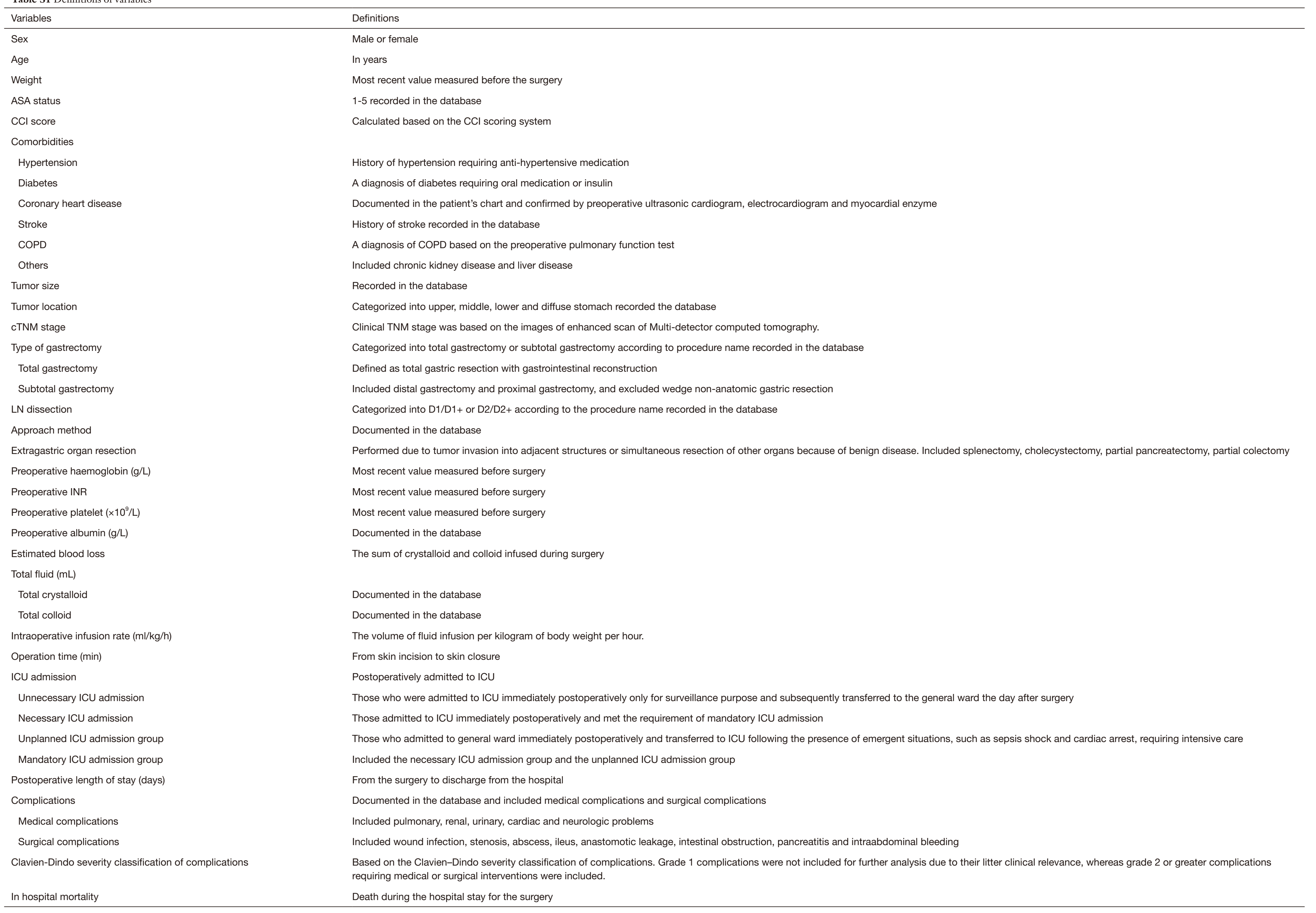

